\title{
Configurable Control System of a Mobile Robot for On - Site Construction of Masonry
}

\author{
G. Pritschow, M. Dalacker and J. Kurz
}

Institute of Control Technology for Machine Tools and Manufacturing Units, University of Stuttgart, Seidenstraße 36, W-7000 Stuttgart 1, Germany

\begin{abstract}
The dramatic shortage of skilled workers and a strong need of improving productivity and efficiency characterizes the situation of masonry construction in Germany today. Therefore, the construction enterprises affected must strengthen their efforts to develop and introduce automation technology for use on the construction site. Such concepts, however, can only be successful, if the national characteristics of masonry construction in Germany are considered, and if the construction industry's demands and needs in terms of flexibility, robustness and economy can be met. Taking these factors into account, the requirements of a mobile robot for on-site construction of masonry have been defined and a highperformance robot control system has been designed.
\end{abstract}

\section{INTRODUCTION}

Masonry, as a production technology, has had a long tradition in the German construction trade and is still of great economic importance. In 1991, artificial bricks and blocks at a total value of 1.6 billion German marks were produced in Germany /1/; masonry comprises $7 \%$ of the total turnover in the construction trade and increases to $11 \%$ in the field of building construction. The special importance of masonry for residential construction can be seen from the number of building permits given for the erection of new buildings. In 1991, the share of masonry in residential buildings was $90.0 \%$, in non-residential buildings as much as $51.8 \% / 2 /$. The market shares of commonly used bricks and blocks were as follows: $42.9 \%$ bricks, $31.6 \%$ sand lime bricks, $14.1 \%$ aerated cement blocks and $11.4 \%$ concrete blocks. Fig. 1 shows the mentioned values by diagrams.

The predominance of private clients and small workshop-like construction enterprises is a characteristic feature of the German bricklaying trade: Two thirds of the apartments erected are situated in buildings with only one or two apartments, 
and $80 \%$ of all construction enterprises employ less than 20 people $/ 1 /$.

In spite of the masons' bad working conditions and high physical strain, bricklaying work is nowadays still mainly done by hand. This is due to the fact that there has been, up to now, no adequate technical support which meets the demands of the industry as far as economical factors and robustness are concerned. Due to the increasing shortage of skilled workers and the need of improved efficiency and productivity, automation technology is likely to play a major role in masonry construction in the near future.

Share of Masonry in

Residential Construction (1990)

Market Shares of Different Masonry Materials (1991)

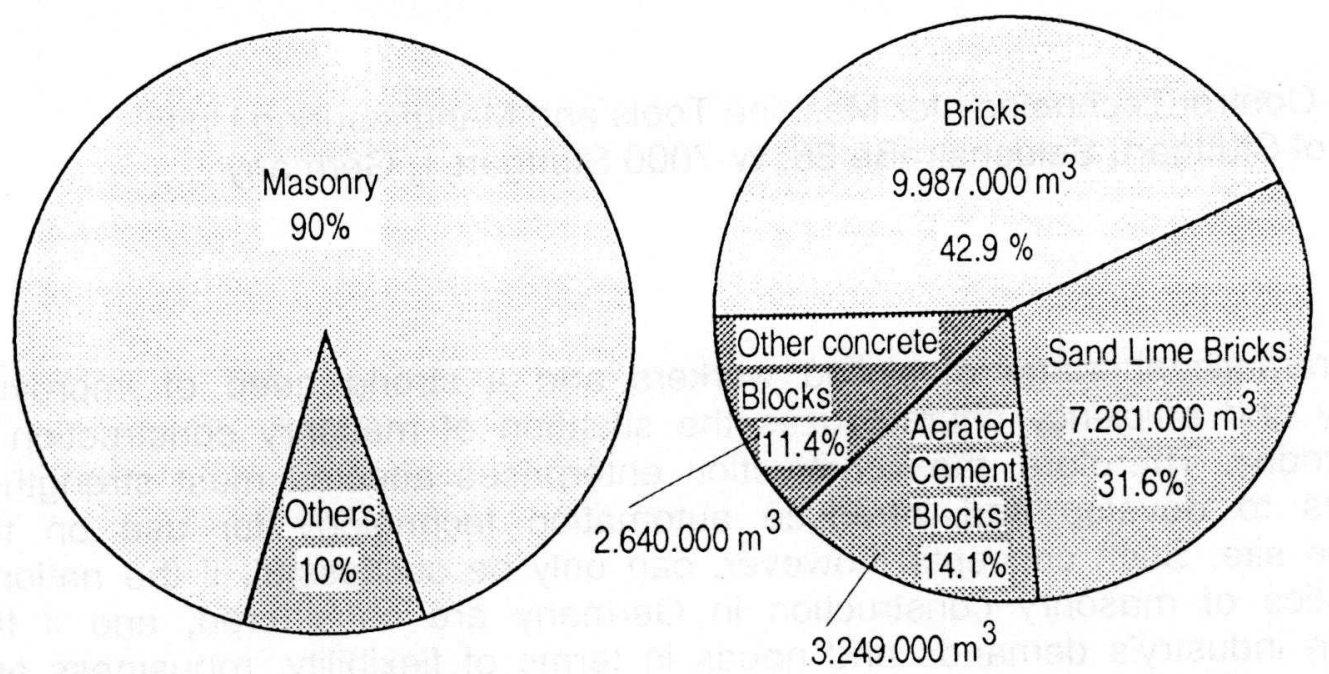

Fig. 1: Significance of masonry construction in Germany /1/

Mechanization and automation technologies for masonry construction presently available in industry are limited to the use of masonry cranes and semi-automatic bricklaying machines on construction sites $/ 3 /$ and to the prefabrication of complete walls in production plants $/ 4 /$. In Germany, these solutions are only of regional importance and, due to lacking flexibility and acceptance, have not been very successful on a large scale $/ 5 /$.

International research activities concentrate upon the development of robotoriented technologies for the use on construction sites. There are fundamental feasibility studies and realization proposals from USA /6/, Russia /7/, Finland /8/ and Germany 19/. Economic aspects of such approaches have been discussed in several papers $/ 10,11 /$, with the results turning out promising. Current research activities in Israel and England are adopted to the respective national building technology: In Israel, gypsum blocks are used for dry wall construction by means of a mobile robot 112/. Research work in the United Kingdom focuses on traditional bricklaying technology using imprecise bricks and thick bonding material. Placing of the bricks is done by a stationary gantry type robot $/ 13 /$. Within the European Community, 3 international R\&D projects concerning automation of masonry construction are currently funded by EUREKA and ESPRIT programs /14,15,16/. 


\section{TECHNOLOGICAL REQUIREMENTS AND PERFORMANCE CHARACTERISTICS OF A BRICKLAYING ROBOT}

The national characteristics of masonry construction in Germany described above show that a simple transfer of automation approaches from other countries to the German conditions will not be successful. The special middle-class structure of German construction enterprises, individual wishes of the clients concerning the ground plan of the buildings as well as the great variety of masonry materials used require an extremly flexible, economical and easy-to-use technology. From the construction industry's point of view, the following demands must be met:

- On-site usage: The technology must be available on the construction site for both new erection and rebuilding of houses.

- Variety: Erection of both exterior and interior walls by the robot, possibility of processing any type of brick or block which is in line with market requirements (especially bricks, sand lime bricks, aerated cement blocks and concrete blocks), application of related bonding technologies( masonry mortar, glue).

- Flexibility: Realization of any ground plan desired by the client.

- Simplicity: Trouble-free integration into the construction process, little stationary equipment, operation by semi-skilled workers.

- Economy: Increased productivity, lower cost.

- Computer integration: Transfer of CAD data generated off-line to the robot control
system.

From these technological requirements mentioned above, the following performance characteristics of a bricklaying robot can be derived:

- Mobility: The working space of a manipulator performing the bricklaying task itself is limited by the reach of its arms. Putting the manipulator onto a mobile platform enables changing the working position, thus extending the working space to the whole floor.

- Large reach: The manipulator's reach should be no less than $2.5 \mathrm{~m}$ to reduce the number of changes of the working position.

- Kinematic structure: The working space of the robot is limited by construction sitespecific bounds such as pallets of masonry material, building machinery or walls and ceilings which have already been completed. Such limitations must be considered when designing a suitable kinematic structure of the robot.

- Small dimensions: The overall dimensions of the mobile robot should be chosen so that passing through door openings is still possible.

- Low weight: The bearing capacity of the floor which the robot moves on is generally limited (a typical value is $500 \mathrm{~kg} / \mathrm{sqm}$ ). Consequently the weight of the robot is to
be kept low.

- High lifting capacity: Economical construction favours the use of large-sized blocks with considerable weights. Therefore, the manipulator's lifting capacity should not fall below $50 \mathrm{~kg}$.

- Fast tool change: Each type of masonry material may require a corresponding tool or handling device. Changing these tools must be possible in a fast and simple

- Safety: The robot itself as well as the operating staff must be protected by 
adequate safety precautions.

- High performance: Economy of the robot is largely influenced by the duration of the duty cycle. The application of intelligent control strategies results in minimum duty cycles.

- Powerful control system: Processing of sensor signals will be necessary for motion generation. That's why a high-performance robot control system with an open architecture and high functionality is required.

- Overall robustness: The bricklaying robot will be operated under rough environmental conditions (rain, heat, dust, vibrations). Fail-safe operation must be guaranteed by a robust construction.

A possible layout of a bricklaying robot with caterpillar tracks and a hydraulic manipulator is shown in fig. 2 .

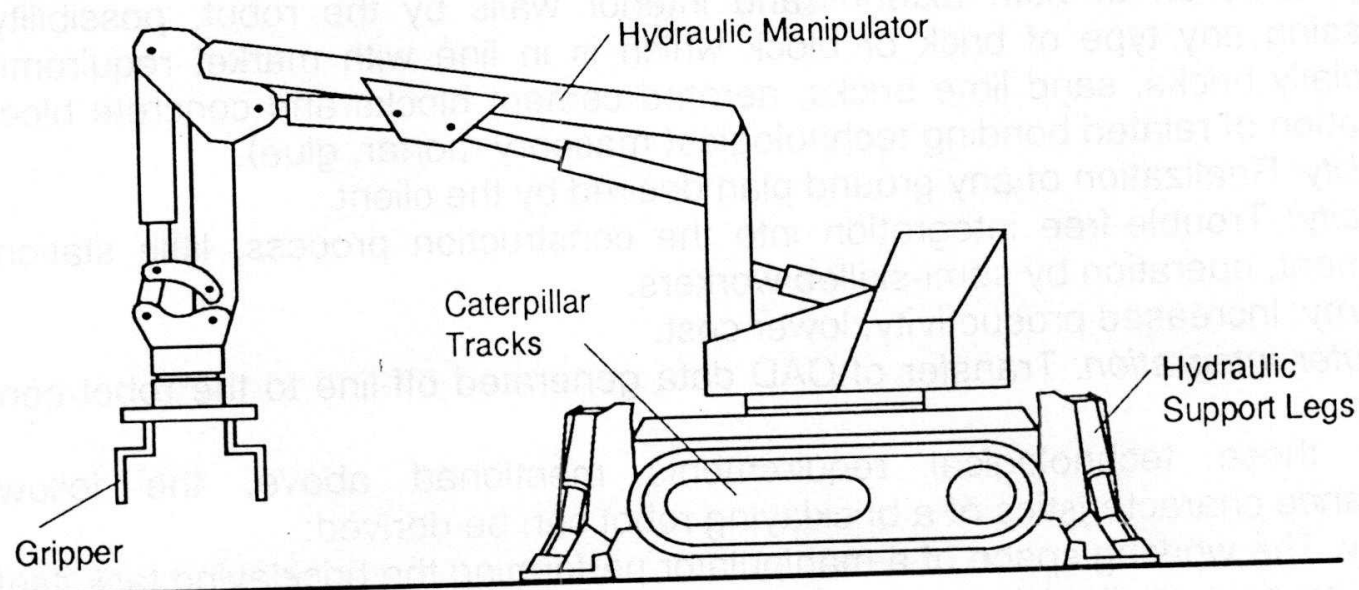

Fig. 2: Possible layout of a bricklaying robot

The hardware structure of the bricklaying robot will not be discussed in more detail. The next chapter focuses on the robot control system.

\section{REQUIREMENTS OF THE ROBOT CONTROL SYSTEM}

The purpose of the control system of the mobile bricklaying robot described above is the generation, execution and supervision of motion sequences for all locomotion, manipulator and handling axes involved in the bricklaying process. As the application is rather complex and a lot of axes will contribute to the motion of the end effector, powerful computer hardware and a realtime operating system are required. The functional profile of the robot control system results in the following requirements:

- Integrated control system for mobile platform and manipulator: The specific tasks of the mobile platform (changing the working position) and the manipulator (performing the bricklaying process itself) must be intgrated into the robot control system. 
- Programming system and CAD/RC - interface: A easy-to-handle user interface must be provided for the generation and input of application programs. While program mode is on, CAD data which have been generated off-line should be directly transferred to the robot control system.

- Sensor data processing: Both positioning of the mobile platform and precise placing of bricks or blocks can not be done without support by proper sensors. The reason for this are inevitable tolerances of the robot and the masonry material. Therefore, adequate sensor interfaces must be available with the robot control system.

- Motion generation: Smooth reference paths have to be generated to avoid overload of the drive units. To achieve this, the dynamic limits of the drives must be taken
into account during interpolation.

- Coordinate transformation: Programming of the robot by the user will in most cases be done in cartesian coordinates. For controlling the drive units, however, joint coordinates will be used. Transformation algorithms must be provided for the conversion of the reference values between the two coordinate systems.

- Fast servo controllers: From the control engineer's point of view, joints of manipulators and industrial robots are featuring substantial elasticities and little damping. In addition, strong non-linearities must be considered if hydraulic drives are used. Powerful servo controllers must be provided for the implementation of the high-level control concepts required.

- Use of industrial standards: Considering marketing requirements of the robot control system, the use of industrial standards is strongly recommended as far as the operating system, the control kernel interfaces, communication protocols and programming languages are concerned.

\section{THE CONFIGURABLE ROBOT CONTROL SYSTEM ISWRC}

The modern, freely configurable robot control system ISWRC has been developed at the Institute of Control Technology for Machine Tools and Manufacturing Units (German abbreviation: ISW) at the University of Stuttgart. The use of modular hardware components and an extremly open system architecture allow simple adaptation of the control system performance to the requirements of the respective application. In this chapter, the components of the control system hardware, the realtime operating system employed and the structure of the control software will be

\subsection{The structure of the control system hardware}

A processor board equipped with a Motorola CPU 68040 is used as a control computer. Communication with several $1 / O$ devices, such as analog-to-digital converters, digital-to-analog converters, evaluation units for incremental encoders and binary $1 / O$ modules, is carried out via an industrial standard VMEbus system. A workstation is available for the development of the control system software which will be downloaded to the target via Ethernet coupling (fig.3). 


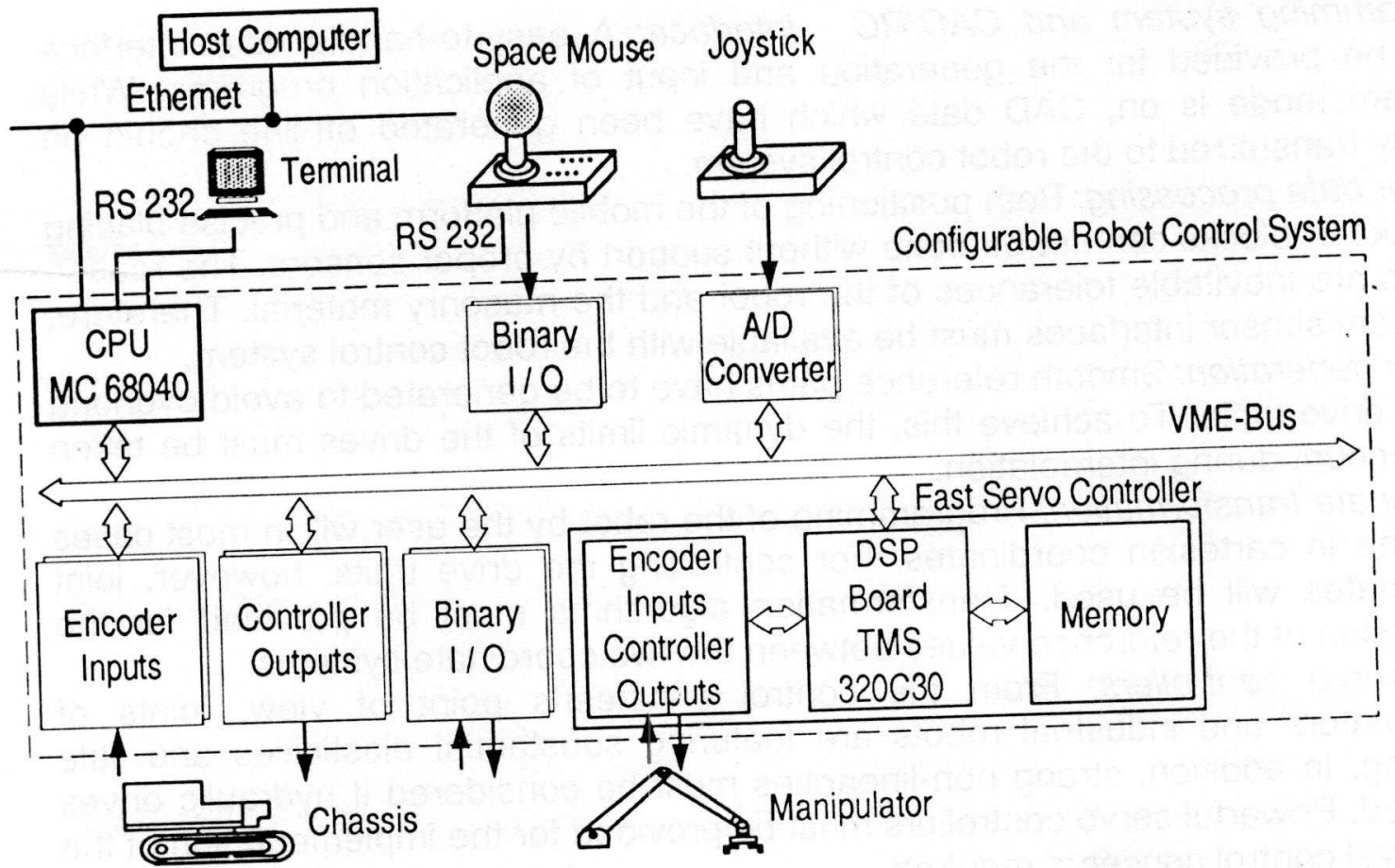

Fig. 3: Hardware structure of the Robot Control System ISWRC

The control system can be operated in either "manual mode" or "program mode". For manual operation, a joystick and a 6-degree-of-freedom space mouse have been provided: the joystick is used for controlling locomotion, whereas the space mouse allows motion generation for a 6 -axes manipulator. Application programs for the program mode are entered via a video terminal and transferred to the control computer via a serial interface.

A fast servo control system based on the digital signal processor TMS $320 \mathrm{C} 30$ is used for position control of the robot joints. Sufficient computational power for the implementation of real-time high-level control algorithms has been provided /17/.

\subsection{The real-time operating system}

Organization and just-in-time execution of single tasks inside the control system such as motion generation or position control is performed by a powerful multitasking real-time operating system. It facilitates the integration of user-specific functions into the control system as well as future changes. The operating system is hardwareindependent and, in addition, offers further advantages such as

- clear task-oriented structure of the control system software,

- short interrupt and task changing times,

- fast and efficient mechanisms for intertask communication and synchronization,

- preemptive scheduling,

- interfaces for data exchange with local and remote file systems,

- services for communication with peripheral devices and external computers. 


\subsection{The structure of the control system software}

The software structure of the control system is shown in fig.4. A programming system forms an interface between the user and the robot control system $/ 18 /$. In

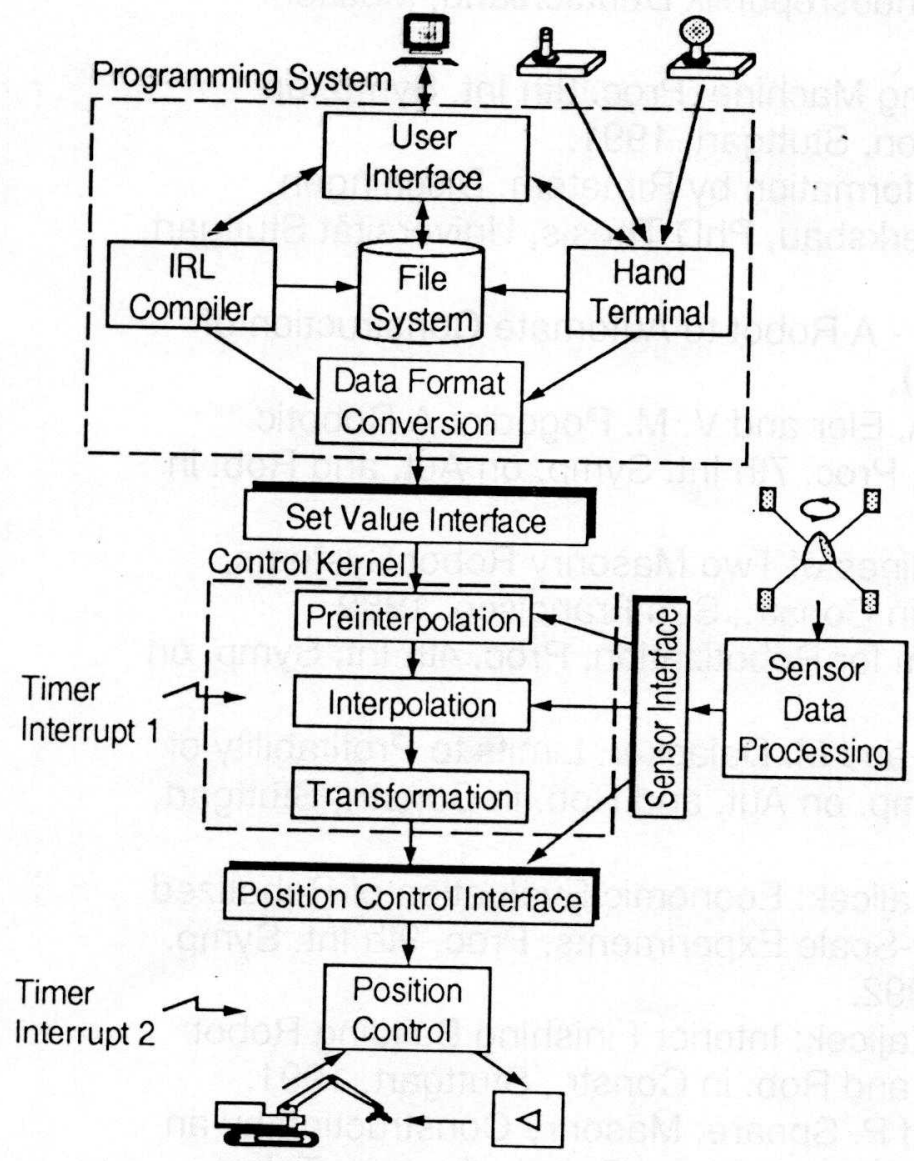

program mode, motion commands are entered as text using the robot programming language IRL (Industrial Robot Language) and compiled afterwards, in manual mode, respective commands are generated from the output signals of the manual control devices described in section 4.1. After a conversion of data formats, the reference values are transferred to the control kernel. Within the control kernel, preinterpolation and transformation functions are executed $/ 19,20 /$. Sensor data may be on-line transmitted to the control kernel for further processing via several interfaces 121\% A servo controller interface has been provided for transmission of transformed joint reference values to the drive units.

Fig.4: Software structure of the Robot Control System ISWRC

\section{CONCLUSIONS}

After a discussion of the national characteristics of masonry construction in Germany, requirements of an automated bricklaying robot and its control system have been defined. An open, configurable robot control system featuring modular hardware components, a hardware-independent real-time operating system, a taskoriented software structure and standard interfaces has been presented. The control system offers both manual and program mode programmable in either cartesian or joint coordinates, extensive sensor data processing capabilities and high-level control kernel functions. It may be easily adopted to any hardware configuration of a
bricklaying robot. 


\section{REFERENCES}

1 Statistisches Bundesamt, Fachserie 4, Reihe 3.1 und 5.1

2 Statistisches Jahrbuch 1991 für die Bundesrepublik Deutschland, MetzlerPoeschel, Stuttgart, 1991.

3 D.Böhm: The Mason's Elevator Handling Machine, Proc. 8th Int. Symp. on Automation and Robotics in Construction, Stuttgart, 1991.

4 Rimatem Fertig-Mauerwerk, product information by Rimatem, Dischingen.

5 J. Laukemper: Automation im Mauerwerksbau, PhD Thesis, Universität Stuttgart, 1991.

6 A. H. Slocum and B. Schena: Blockbot - A Robot to Automate Construction of Cement Block Walls, Robotics 4 (1988).

7 E. Malinovsky, E. A. Borschewski, E. A. Eler and V. M. Pogodin: A Robotic Complex for Brick-Laying Applications, Proc. 7th Int. Symp. on Aut. and Rob. in Constr., Bristol, 1990.

8 H. Lehtinen, E. Salo and H. Aalto: Outlines of Two Masonry Robot Systems, Proc. 6th Int. Symp. on Aut. and Rob. in Constr., San Francisco, 1989.

9 T. A. Bock: Concept of Building System for Robotization, Proc. 4th Int. Symp. on Rob. in Constr., Haifa, 1987.

10 G. Drees, J. Laukemper, G. Pritschow and M. Dalacker: Limits to Profitability of Automated Masonry, Proc. 8th Int. Symp. on Aut. and Rob. in Constr., Stuttgart, 1991.

11 Y. Rosenfeld, A. Warszawski and U. Zajicek: Economic Evaluation of Robotized Interior Finishing Works Based on Full-Scale Experiments, Proc. 9th Int. Symp. on Aut. and Rob. in Constr., Tokyo, 1992.

12 Y. Rosenfeld, A. Warszawski and U. Zajicek: Interior Finishing Building Robot "TAMIR", Proc. 8th Int. Symp. on Aut. and Rob. in Constr., Stuttgart, 1991.

13 D. Chamberlain, S. Ala, J. Watson and P. Speare: Masonry Construction by an Experimental Robot, Proc. 9th Int. Symp. on Aut. and Rob. in Constr., Tokyo, 1992.

14 EU 377 FAMOS BRICK - Highly Flexible Automated and Integrated Bricklaying System, EUREKA project (current).

15 EU 542- Mechanization of Bricklaying Technology on the Building Site, EUREKA project (current).

16 ROCCO - Robot Assembly System for Computer Integrated Construction, ESPRIT project No. 6450 (current).

17 W. Philipp and W. Scholich: Fließkomma-Signalprozessor-System für komplexe Regelungen, Elektronik Entwicklung 7 (1990).

18 G. Pritschow and O. Frager: Roboterzellen - Programmierung: Die Sprache IRL und der Zwischencode ICR, Robotersysteme 8 (1992).

19 M. Jantzer: Bahnverhalten und Regelung fahrerloser Transportsysteme ohne Spurbindung, Springer, 1990.

20 M. Bauder: Konfigurierbare Robotersteuerung mit allgemeiner Transformation, Springer, 1992.

21 G. Pritschow and A. Horn: Dynamik derzeitiger Sensorregelkreise für Industrieroboter, Robotersysteme 7 (1991). 